\title{
THE
}

1999

\section{Kuroshio Meanders in the East China Sea}

Charles James

University of Rhode Island

Mark Wimbush

University of Rhode Island, mwimbush@uri.edu

Hiroshi Ichikawa

Follow this and additional works at: https://digitalcommons.uri.edu/gsofacpubs

\section{Citation/Publisher Attribution}

James, C., Wimbush, M., \& Ichikawa, H. (1999). Kuroshio Meanders in the East China Sea. J. Phys. Oceanogr., 29, 259-272. doi: 10.1175/1520-0485(1999)0292.0.CO;2

Available at: https://doi.org/10.1175/1520-0485(1999)029<0259:KMITEC>2.0.C0;2

This Article is brought to you for free and open access by the Graduate School of Oceanography at DigitalCommons@URI. It has been accepted for inclusion in Graduate School of Oceanography Faculty Publications by an authorized administrator of DigitalCommons@URI. For more information, please contact digitalcommons-group@uri.edu. 


\title{
Kuroshio Meanders in the East China Sea
}

\author{
Charles JAMES* AND MARK Wimbush \\ Graduate School of Oceanography, University of Rhode Island, Narragansett, Rhode Island \\ HIROSHI ICHIKAWA \\ Faculty of Fisheries, Kagoshima University, Kagoshima, Japan
}

(Manuscript received 12 June 1997, in final form 9 April 1998)

\begin{abstract}
An array of seven inverted echo sounders was moored along and across the Kuroshio in the East China Sea for more than one year. The data from this array show evidence of energetic meanders with periods of 7,11 , and 16 days. The respective phase velocities of these meanders are 28,20 , and $17 \mathrm{~km}$ day $^{-1}$ downstream. The 7- and 16-day waves are intermittent, but the 11-day waves are present throughout the deployment.

The instability responsible for these waves is investigated with a spectral numerical model applied to a background state representing the Kuroshio in this region. The fastest-growing instability from the model has $e$-folding growth time of 2 days, period of 12 days, and phase velocity of $18 \mathrm{~km}^{-1 a{ }^{-1}}$ downstream. It appears to be a close representation of the 11-day wave seen in the observational data.

Such a model has been previously used to represent meanders in the Gulf Stream at similar latitudes off the east coast of the United States. The Kuroshio meanders have approximately half the phase velocity and twice the period of the Gulf Stream meanders. To investigate the reasons for these differences, the flow and topography of the model background state were varied. The slower phase velocity and longer period of the Kuroshio meanders appear to be consequences of the deeper shelf and lower transport, with a modifying effect due to the difference in cross-shelf positioning of the current core (more over-the-shelf in the case of the Kuroshio).
\end{abstract}

\section{Introduction}

The Kuroshio, in the northwest Pacific, is one of the world's major western boundary currents. It flows northward off the east coast of Taiwan before entering the East China Sea (ECS), where it flows in a northeastward direction over the Chinese continental slope (Fig. 1). Near $30^{\circ} \mathrm{N}$ it turns to the east, exiting the ECS through Tokara Strait and then flowing eastward off the south coast of Japan. The Kuroshio, flowing through the ECS, can be compared to the Gulf Stream as it flows from Florida to the Carolinas. Within the ECS, the Kuroshio transports an average of $23.7 \pm 2.0 \mathrm{~Sv}\left(\mathrm{~Sv} \equiv 10^{6} \mathrm{~m}^{3}\right.$ $\mathrm{s}^{-1}$ ) (Ichikawa and Beardsley 1993); in contrast, the Gulf Stream off Florida transports 30-37 Sv (Richardson et al. 1969). Both currents are strongly influenced by the local topography, but the Chinese shelf is wider

\footnotetext{
* Current affiliation: School of Earth Sciences, Flinders University of South Australia, Adelaide, South Australia.

Corresponding author address: Dr. Charles James, FIAMS, School of Earth Sciences, Flinders University of South Australia, GPO Box 2100, Adelaide, South Australia 5001

E-mail: Charles.James@es.flinders.edu.au
}

and deeper than the Florida shelf. Also, the Ryukyu Ridge and island chain forms a partial barrier on the offshore side of the Kuroshio; but while the Bahama Banks are an even more constricting barrier to the Gulf Stream, they are only present off southern Florida.

In the Gulf Stream, there have been a number of studies to determine the low-frequency variability of the system. During a five-month study in the South Atlantic Bight (SAB) off the southeastern United States, Lee and Atkinson (1983) report disturbances with periods from 5 to 9 days traveling $43-60 \mathrm{~km}$ day $^{-1}$ downstream. These disturbances grow with downstream distance between the Florida Straits $\left(26^{\circ} \mathrm{N}\right)$ and the Charleston Bump $\left(31^{\circ} \mathrm{N}\right)$; at $28.5^{\circ} \mathrm{N}$ they have lateral excursions with standard deviation $6 \mathrm{~km}$ (Bane and Brooks 1979).

In contrast to the Gulf Stream, most time series observations of the Kuroshio are of short duration, usually days to weeks. Table 1 presents the periods and wavelengths reported in these ECS Kuroshio studies together with the Lee and Atkinson (1983) Gulf Stream results at similar latitudes. The rough similarity of periods and wavelengths in these two boundary currents suggests dynamic similarity of their fluctuations. But, because there are no previous time series measurements from the Kuroshio in the ECS of more than a few weeks 


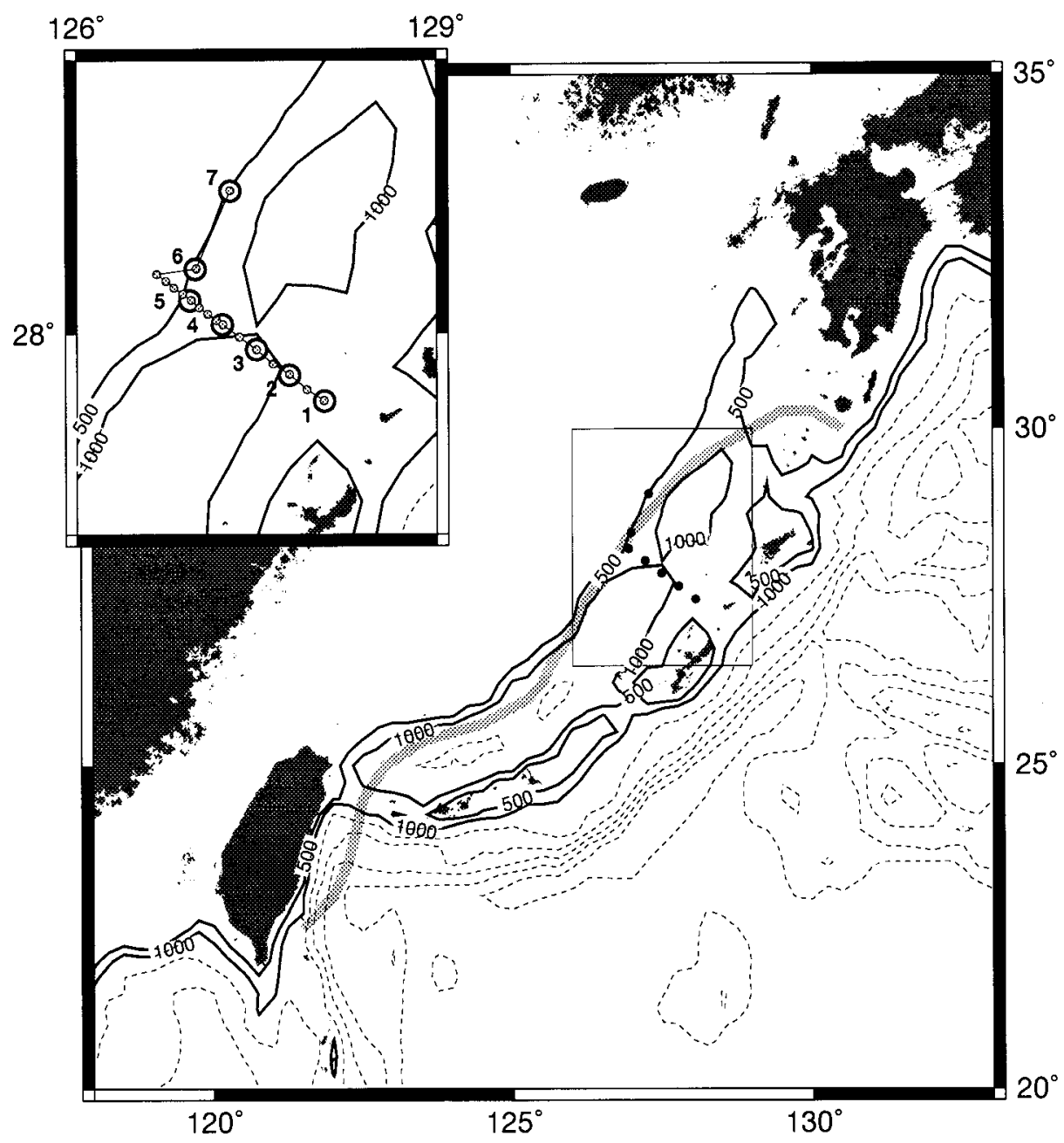

FIG. 1. Map of the Kuroshio in the East China Sea. Gray line shows mean Kuroshio path, taken from Sun and Su (1994). The 500-m and 1000-m isobaths are shown as solid contours; dashed contours (unlabelled) are at 1000-m intervals. The IES array is indicated by black dots. Inset figure shows a closeup of the IES array, with numbered open circles representing the IESs, small gray circles representing the location of CTD casts, and the line representing the ADCP-data track.

duration, little reliability can be attached to the numbers given for the Kuroshio in Table 1.

Previous numerical studies of the Gulf Stream have found fast-growing instabilities with periods and phase velocities similar to those seen in the observational data. Specifically, a spectral model of instabilities in the SAB by Xue and Mellor (1993) revealed fastest-growing meanders with periods of 5.4 days.

Although the Kuroshio and the Gulf Stream are both major western boundary currents and show similarwavelength meanders, the phase velocities of meanders in the Gulf Stream appear to be 2-3 times those in the

TABLE 1. Previous observations and numerical study (bottom row) showing periods and wavelengths of propagating Kuroshio (K) meanders in the ECS and Gulf Stream (GS) meanders off northern Florida.

\begin{tabular}{lcrr}
\hline \multicolumn{1}{c}{ Study } & Current & Period (day) & $\begin{array}{r}\text { Downstream phase } \\
\text { velocity (km day }-1)\end{array}$ \\
\hline Sugimoto et al. (1988) & K & $11-14$ & 26 \\
Qiu et al. (1990) & K & $14-20$ & $300-350$ \\
Ichikawa and Beardsley (1993) & K & $8-23$ & $100-150$ \\
Ichikawa (1993) & K & $13-16$ & $150-375$ \\
Lee and Atkinson (1983) & GS & $5-9$ & $100-300$ \\
Xue and Mellor (1993) & GS & 5.4 & $215-540$ \\
\hline
\end{tabular}


Kuroshio. Qiu et al. (1990) have conjectured that this may be due to the differences in shelf depth. In fact, there are a number of differences, both in topography and in velocity profile, that might contribute to this difference in phase velocities. An important goal of this study is to identify which, if any, of these physical parameters are responsible for the observed differences in meander properties. This study of the Kuroshio in the ECS consists of two separate parts: 1) a field study, with time series lasting over one year, and 2) a numerical modeling study of the flow instability.

\section{The field study}

\section{a. Description}

To carry out a comparison of the dynamics of the Kuroshio in the ECS and the Gulf Stream in the SAB, Kuroshio observations lasting at least several months were needed. These were provided by an array of inverted echo sounders (IES) moored in the ECS northwest of Okinawa for 14.5 months (Fig. 1). All the IESs-except IES 3 at the center of the Okinawa Trough-successfully recorded acoustic travel time throughout their deployment. In the Kuroshio (James and Wimbush 1995), as in the Gulf Stream (Watts and Rossby 1977; Trivers and Wimbush 1994), acoustic travel time as measured by an IES is well correlated with dynamic height. All the IESs used in this study also measured near-bottom pressure with precision pressure gauges.

The IES records (data interval $1 \mathrm{~h}$ ) were converted to surface dynamic height relative to $500 \mathrm{db}$, according to procedures described in detail in James et al. (1994). The resulting detided time series of dynamic height variations were analyzed to identify spectral peaks and to determine amplitude, wavelength, and propagation speed of the strongest fluctuations. In October 1992, a few days before the IESs were recovered, CTD casts and ADCP profiles were taken at the locations shown in Fig. 1. The results of the CTD and ADCP survey are shown in Fig. 2, where the cross-stream origin is taken to be $100 \mathrm{~km}$ shoreward of the shelf break to be consistent with model results in section 3 .

\section{b. Data analysis}

Except where otherwise stated, all spectral analyses were carried out using 111-day ensembles, 50\% overlapping, and a Hanning window. Autospectra of the dynamic height signal, computed from the individual IES records, revealed bands of energy in the three downstream IESs, with periods between 5 and 20 days (Fig. 3 , left panels). Cross-spectral analysis indicated coherent signals within these energy bands (Fig. 3, right panels); these signals had phase velocities between 18 and $28 \mathrm{~km} \mathrm{day}^{-1}$ in the downstream (northeastward) direction.

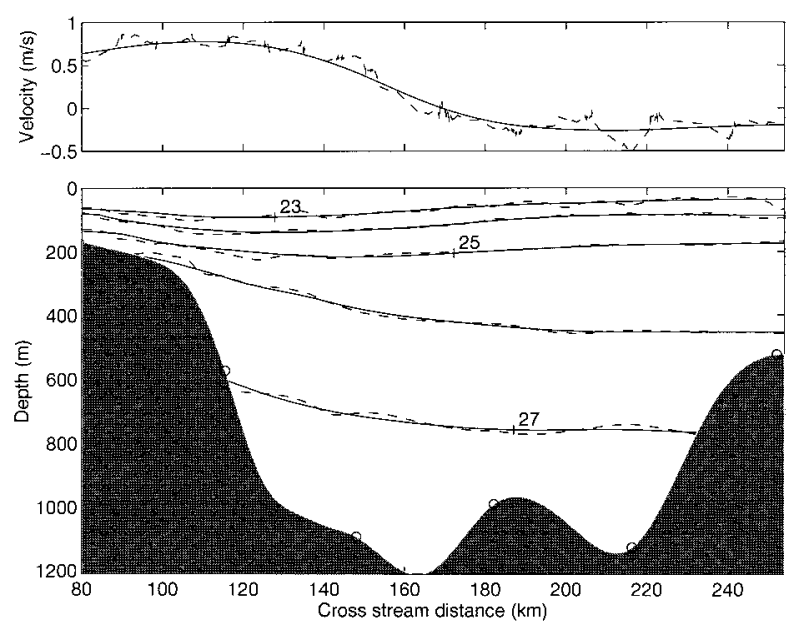

FIG. 2. Hydrographic data from the recovery cruise. Top panel shows the 100-km filtered (solid) and unfiltered (dashed) ADCPderived surface velocity component perpendicular to the transect. Bottom panel shows the $100-\mathrm{km}$ filtered (solid) and unfiltered (dashed) density profiles and measured bathymetry. Open circles represent the IES bottom locations. Velocity is in $\mathrm{m} \mathrm{s}^{-1}$. Density is given as $\sigma_{t}$, contour interval $1 \mathrm{~kg} \mathrm{~m}^{-3}$.

We used empirical orthogonal function (EOF) analysis to isolate the dominant structure of the dynamic height fields. To allow for the apparent wave propagation in the downstream direction, lags between IESs 5, 6, and 7 (Fig. 1) were introduced so as to maximize the variance represented by the first-mode EOF. The dynamic height data from IES 6 and IES 7 were lagged, relative to IES 5, by 1.1 and 4.1 days, respectively. This corresponds to a signal downstream propagation speed of $23.6 \mathrm{~km} \mathrm{day}{ }^{-1}$, which is consistent with the results of the cross-spectral analysis. The resulting first-mode dynamic height EOF contains $61 \%$ of the variance. Based on Selection Rule N (Preisendorfer 1988), the first-mode EOF must contain more than $19 \%$ of the variance to be significant at the $90 \%$ confidence level.

The autospectrum of the resulting first-mode temporal EOF is shown in Fig. 4, together with $90 \%$ confidence intervals determined by Monte Carlo simulation. There are three energetic peaks, at 7-day, 11-day, and 16-day periods. These peaks are statistically significant at the $90 \%$ confidence level.

In order to determine whether these signals were varying in time, complex demodulations (CDM) were performed on the first-mode temporal EOFs. CDM is a method of heterodyning a particular frequency of a time series to zero, and then low-pass filtering to find the slowly varying amplitude and phase (Bingham et al. 1967). The phase of the CDM gives an indication of the frequency stability of the signal. When the phase is constant the selected frequency matches the frequency of the signal in the record. When the phase is decreasing, the selected frequency is too high; when the phase is increasing, the selected frequency is too low.

Figure 5 shows the amplitudes and phases of the CDM 


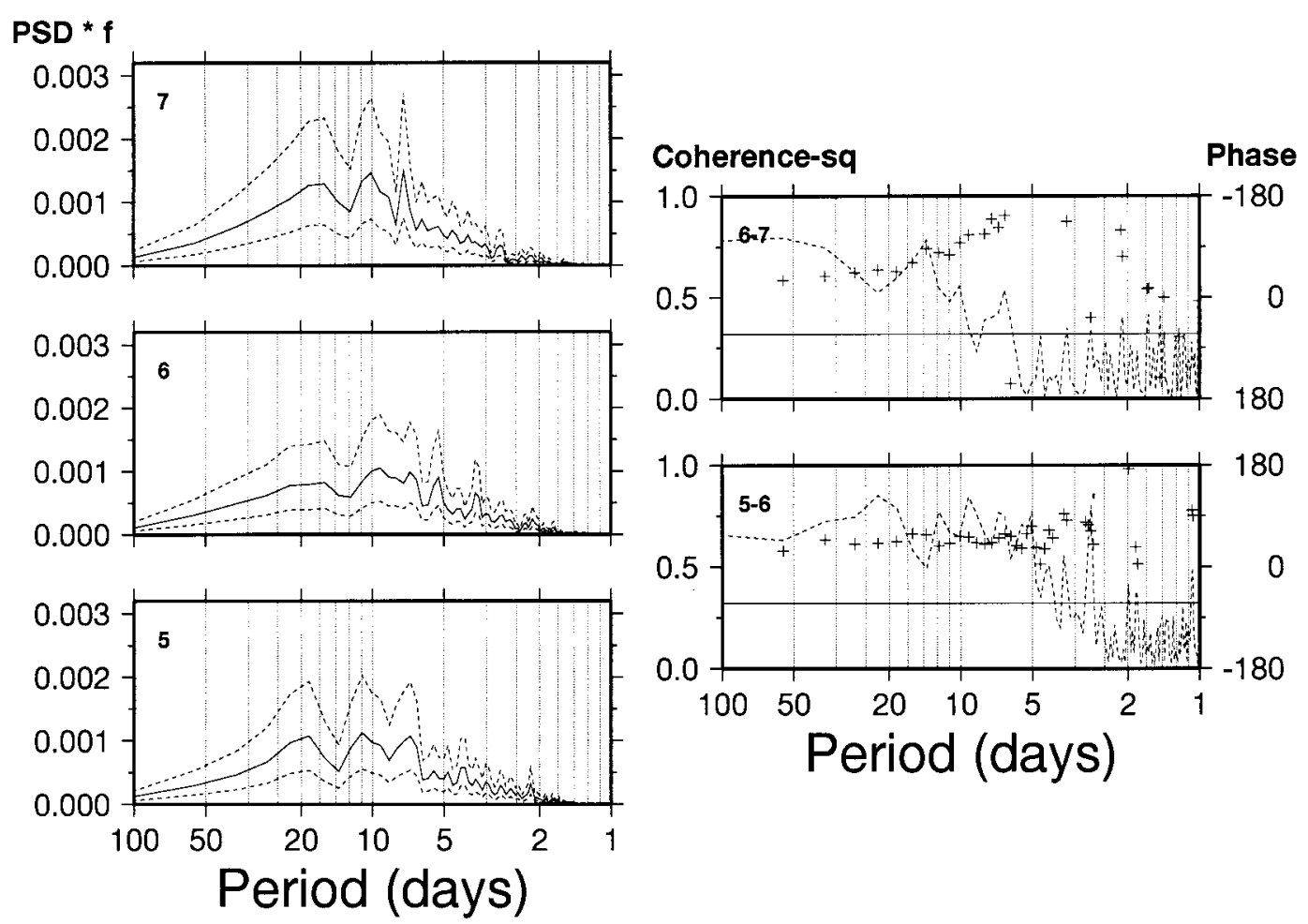

FIG. 3. Spectral analysis of the downstream IESs 5-7. In each panel, the IES number or numbers are shown at top left. Left panels show autospectra with $90 \%$ confidence interval indicated by dashed lines. Right panels show crossspectra: coherence-squared (dashed line) and phase lag in degrees of second IES relative to first (crosses). The solid line indicates the $90 \%$ confidence level for coherence; phase is only shown where coherence exceeds this level.

for the periods corresponding to the three spectral peaks. The amplitude of the 7-day wave becomes strong in the middle of the record between days 380 and 460 (16 Jan 1992-5 Apr 1992). During this period the phase is stable. The amplitude of the 11-day wave is fairly steady, with the exception of a slight weakening around day 350 (17 Dec 1991) and strengthening toward the end of the record. The phase is stable, except at these times. The slightly increasing phase near the end of the record indicates that the period of the signal is slightly less during that time. The amplitude of the 16-day wave is very variable, being strongest near the beginning of the record, before day 300 (28 Oct 1991), and almost vanishing at day 570 (24 Jul 1992). The phase is fairly

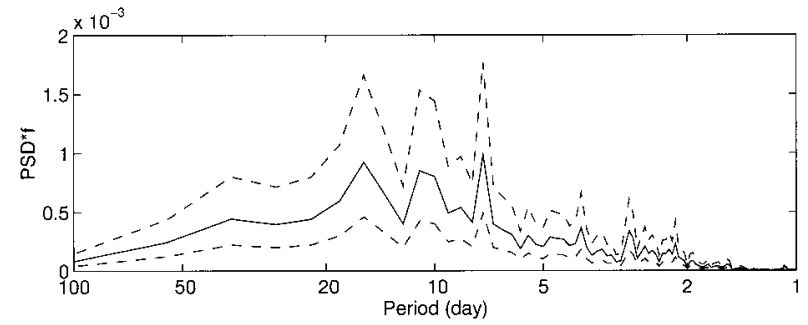

FIG. 4. Energy-preserving spectrum of first-mode dynamic height EOF, computed as described in text; $90 \%$ confidence intervals are indicated by dashed lines. stable except near the point of weakest amplitude at day 570.

To study the cross-stream spatial structure of the disturbances, we carried out an EOF analysis on the data from the cross-stream IESs (IES 1-5). Figure 6 shows the amplitudes of the first two dynamic height EOFs,
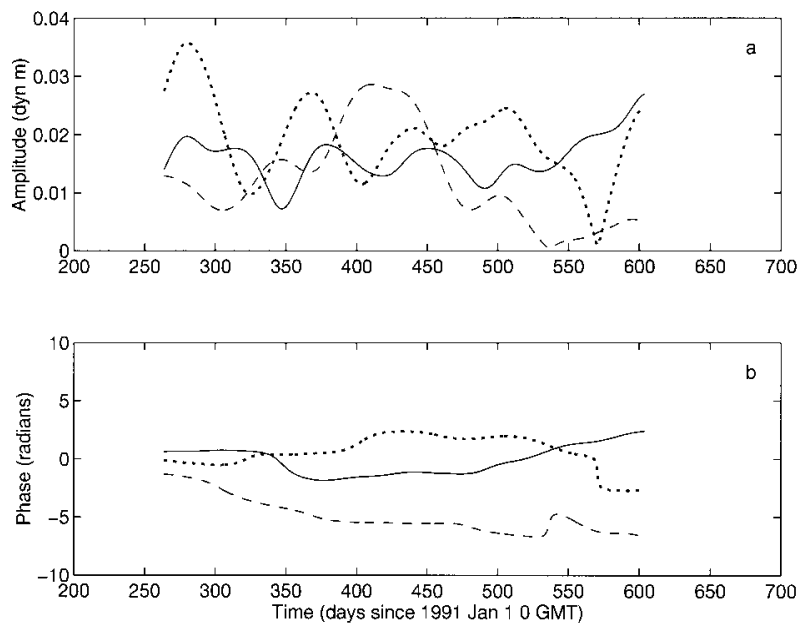

FIG. 5. Amplitude (a) and phase (b) of the 7-day (dashed), 11-day (solid), and 16-day (dotted) complex demodulation of the dynamic height first-mode EOF time series. 


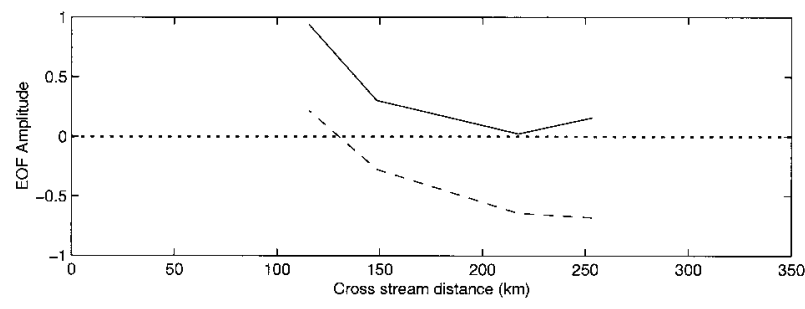

FIG. 6. EOF spatial structures of data from the cross-stream leg of the IES array (dynamic height from IESs 1, 2, 4, and 5). Solid line is first mode; dashed line is second mode.

plotted against cross-stream distance. The first EOF accounts for $57 \%$ of the variance, is all of one sign, and has maximum amplitude at the site closest to the shelf break. The variance exceeds that required for significance at the $90 \%$ confidence level. This structure appears to represent a meandering of the Kuroshio since the peak is near the Kuroshio core where the pycnocline tilt is a maximum; as the core meanders, the density field variations are in phase everywhere and are greatest where the pycnocline tilt is the greatest. The second EOF accounts for $33 \%$ of the variance and is also significant at the $90 \%$ confidence level. The structure of the second EOF implies a varicose mode, with dynamic height variation of opposite sign on either side of the Kuroshio core at about $x=120 \mathrm{~km}$.

Since the spatial structure of the first-mode dynamic height EOF represents meandering, the temporal structure can be thought of as indicating the location of the core of the Kuroshio. Thus, Figure 7 indicates the $\mathrm{Ku}$ roshio was very near its mean position at the time of the CTD and ADCP sections. The standard deviation of the temporal record is 5-dyn $\mathrm{cm}$. Assuming an average core velocity of $1 \mathrm{~m} \mathrm{~s}^{-1}$, this represents a Kuroshio meandering with standard deviation of $7 \mathrm{~km}$, consistent with the $14-\mathrm{km}$ range of seasonal variation in the $\mathrm{Ku}-$ roshio axis position observed by Ichikawa (1993) at the nearby PN line.

To probe the dynamic height records for wave phenomena, we used frequency-domain empirical orthogonal function (FDEOF) analysis (Wallace and Dickinson 1972). FDEOFs can be used to compute the phase relationships of wavelike signals propagating through a dataset. For a given FDEOF the significance threshold depends on the number of degrees of freedom, or independent observations contributing to the calculation,

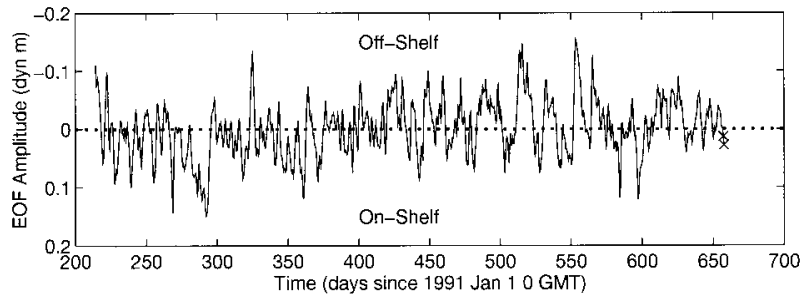

FIG. 7. First-mode EOF temporal structure of data from the crossstream leg of the IES array. On-shelf and off-shelf displacements are indicated assuming a meandering mode. Beginning and end times of CTD/ADCP survey are marked by " $\times$."

and can be determined using a simple Fisher $F$ test (Kontoyiannis and Watts 1994). The cross-spectra for these FDEOFs were computed as before, except 55.5day ensembles were used for periods of 7 days or less. In addition, band averaging of 3, 5, and 9 bands was used, at long, intermediate, and short periods, respectively, giving the bandwidths shown in Table 2. This table gives the results of the FDEOF analysis of IESs 5-7 (downstream leg of the array) at the periods of the three spectral peaks. All the first modes satisfy the significance condition based on the $F$ test at the $90 \%$ confidence level. The FDEOF analysis reveals how wavelength and phase velocity depend on period. Figure 8 shows phase velocity increasing with increasing frequency for periods from 4 to 55 days.

The wave characteristics observed in this study are similar to those reported by other investigators (Table 1). In comparison to the Gulf Stream, the wavelengths of these waves are roughly the same, but the phase velocities are less by about a factor of 2 . Since these results are in good agreement with other Kuroshio observations, it appears that there is a real difference in phase velocities between the Kuroshio and Gulf Stream meanders. In the next section we describe a model used to investigate how the various physical differences between the Kuroshio and the Gulf Stream affect the wave characteristics of their instabilities.

\section{The model \\ a. Description}

The Moore and Peltier (1987) model of atmospheric frontal instability was adapted by Xue and Mellor (1993) to study Gulf Stream instability in the South

TABLE 2. Dynamic height first-mode results from FDEOF analysis. The fourth column shows the ratio of first-mode variance to secondmode variance. For mode 1 to be significant at the $90 \%$ level, this ratio must exceed 1.8 for 21 degrees of freedom (DOF), 1.6 for 35 DOF, and 1.3 for 126 DOF. The fifth and sixth columns show the wavelength and downstream phase-velocity averages and ranges computed from the phase change in the first-mode FDEOF from IES 5 to IES 6 and from IES 6 to IES 7.

\begin{tabular}{cccccc}
\hline \hline Period (days) & Bandwidth (cpd) & DOF & Variance ratio & Wavelength $(\mathrm{km})$ & $\begin{array}{c}\text { Phase velocity } \\
\left(\mathrm{km} \text { day }^{-1}\right)\end{array}$ \\
\hline 15.86 & 0.027 & 21 & 5.5 & $265.1 \pm 101.6$ & $16.7 \pm 6.4$ \\
11.10 & 0.045 & 35 & 3.7 & $216.6 \pm 43.6$ & $19.5 \pm 3.9$ \\
6.94 & 0.162 & 126 & 2.6 & $195.6 \pm 24.3$ & $28.2 \pm 3.5$ \\
\hline
\end{tabular}




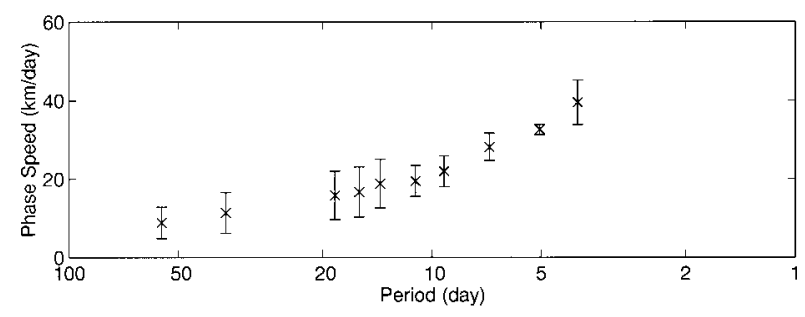

FIG. 8. Downstream phase velocity of first-mode FDEOF for IESs 5-7 as a function of period. Bars indicate the range of values computed from the FDEOF phase change from IES 5 to IES 6, and from IES 6 to IES 7.

Atlantic Bight. Important changes to the original code included a coordinate transformation to include bottom topography, a change in the horizontal basis functions to fit coastal boundary conditions, and a new approach to finding the barotropic pressure.

The model uses the primitive equations, linearized around a background state. The equations are defined using a right-handed coordinate system: $x$ cross-stream, $y$ downstream, $z$ vertically upward from the sea surface. The background current and topography are uniform in the $y$ direction. The background state consists of a velocity field $V(x, z)$, a buoyancy field $B(x, z)$, and topography $h(x)$. Buoyancy is defined as $B=-g \rho(x, z) /$ $\rho_{0}$, where $g$ is the acceleration due to gravity, $\rho(x, z)$ is the background density field, and $\rho_{0}$ is a reference density. Therefore, from thermal wind balance,

$$
f \frac{\partial V}{\partial z}=\frac{\partial B}{\partial x},
$$

where $f$ is the Coriolis parameter. In terms of this background state, the primitive equations become

$$
\begin{aligned}
\left(\frac{\partial}{\partial t}+V \frac{\partial}{\partial y}\right) u-f v+\frac{1}{\rho_{0}} \frac{\partial p}{\partial x} & =0 \\
\left(\frac{\partial}{\partial t}+V \frac{\partial}{\partial y}\right) v+f u+u \frac{\partial V}{\partial x}+w \frac{\partial V}{\partial z}+\frac{1}{\rho_{0}} \frac{\partial p}{\partial y} & =0 \\
b-\frac{1}{\rho_{0}} \frac{\partial p}{\partial z} & =0 \\
\frac{\partial u}{\partial x}+\frac{\partial v}{\partial y}+\frac{\partial w}{\partial z} & =0 \\
\left(\frac{\partial}{\partial t}+V \frac{\partial}{\partial y}\right) b+u \frac{\partial B}{\partial x}+w \frac{\partial B}{\partial z} & =0
\end{aligned}
$$

where $u, v$, and $w$ represent the $x, y$, and $z$ components of perturbation velocity; $p$ is perturbation pressure; and $b$ is perturbation buoyancy. The boundary conditions are

$$
\begin{aligned}
u & =0 & & \text { at } x=0 \\
p, u, \text { and } v & \rightarrow 0 & & \text { as } x \rightarrow \infty \\
w & =0 & & \text { at } z=0 \\
w & =-u \frac{\partial h}{\partial x} & & \text { at } z=-h(x) .
\end{aligned}
$$

The cross section is mapped to a rectangular domain:

$$
\begin{aligned}
& \zeta=1+\frac{z}{h(x)} \\
& \omega=w-(\zeta-1) u \frac{\partial h}{\partial x} .
\end{aligned}
$$

We assume downstream perturbations of the form

$$
\begin{aligned}
u & =\operatorname{Re}\left[\tilde{u}(x, \zeta) e^{i(\sigma t+\beta y)}\right] \\
v & =\operatorname{Re}\left[i \tilde{v}(x, \zeta) e^{i(\sigma t+\beta y)}\right] \\
\omega & =\operatorname{Re}\left[\tilde{\omega}(x, \zeta) e^{i(\sigma t+\beta y)}\right] \\
b & =\operatorname{Re}\left[i \tilde{b}(x, \zeta) e^{i(\sigma t+\beta y)}\right] \\
p & =\operatorname{Re}\left[i \tilde{p}(x, \zeta) e^{i(\sigma t+\beta y)}\right] .
\end{aligned}
$$

Here the downstream wavenumber of the perturbation is $\beta$ and $\sigma=\sigma_{r}+i \sigma_{i}$, where $\sigma_{r}$ is the perturbation frequency and $-\sigma_{i}$ is the growth rate. Using a spectral technique, the two-dimensional structure variables are decomposed into a Fourier series:

$$
\begin{gathered}
\tilde{u}=\sum_{\nu=0}^{\infty} \sum_{\lambda=0}^{\infty} u_{\lambda \nu} E_{\nu} \psi_{\lambda} \\
\tilde{v}=\sum_{\nu=0}^{\infty} \sum_{\lambda=0}^{\infty} v_{\lambda \nu} E_{\nu} \phi_{\lambda} \\
\tilde{\omega}=\sum_{\nu=0}^{\infty} \sum_{\lambda=0}^{\infty} \omega_{\lambda \nu} F_{\nu} \phi_{\lambda} \\
\tilde{p}=\sum_{\nu=0}^{\infty} \sum_{\lambda=0}^{\infty} p_{\lambda \nu} E_{\nu} \phi_{\lambda} \\
\tilde{b}=\sum_{\nu=0}^{\infty} \sum_{\lambda=0}^{\infty} b_{\lambda \nu} F_{\nu} \phi_{\lambda},
\end{gathered}
$$

where, for domain width $L$,

$$
\begin{array}{ll}
E_{\nu}=\cos (\nu \pi \zeta) \quad \phi_{\lambda}=\cos \left(\frac{\lambda \pi x}{L}\right) \\
F_{\nu}=\sin (\nu \pi \zeta) & \psi_{\lambda}=\sin \left(\frac{\lambda \pi x}{L}\right) .
\end{array}
$$

The series is truncated using a triangular scheme: $\nu=$ $0, \cdots, N ; \lambda=0, \cdots, N-\nu$, where $N$ is called the truncation level. When a value of $\beta$ is specified, the model solves for $\sigma$ and the coefficients of the truncated series. Details of the implementation of the spectral model are given in James (1996) and Xue and Mellor (1993). 


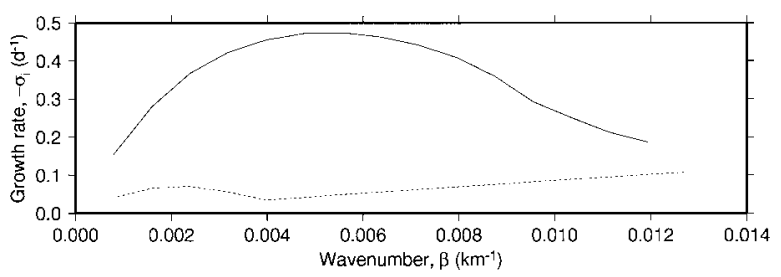

FIG. 9. Computed maximum growth rates for ECS topography model runs (truncation level $N=30$ ) with no background flow (dashed line) and Kuroshio background flow (solid line).

\section{b. Performance}

For conditions representing the Gulf Stream in the SAB, Xue (1991) found the model converged with increasing $N$ and showed that changes in model results, using a realistic background state, were very small between $N=25$ and $N=27$. In their article, Xue and Mellor (1993) used $N=28$. It should also be pointed out that convergence tends to be faster at low wavenumbers, so the appropriate choice of $N$ will depend on the wavelength of the instability being studied. For this study, if the growth rate and phase velocity of the most unstable mode do not change significantly (less than $5 \%$ ) between consecutive $N$, the model is assumed to have converged. Convergence for each background state discussed here is demonstrated in James (1996).

Xue (1991) noticed that an inconsistency in the boundary conditions of the buoyancy equation could give rise to spurious growth rates, even in the absence of any forcing. Nevertheless, for a simple topography these growth rates were at least an order of magnitude smaller than the expected real growth rates. Since the ECS topography is more complicated than Xue's test topography, we needed to confirm this behavior for the ECS. To determine this error for the ECS, the model was run with a motionless background state $(V=0$ everywhere) and with topography representing the ECS (see next section). Without flow there is no energy source to feed growing perturbations, therefore the system should be stable $\left(\sigma_{i} \geq 0\right)$. Figure 9 shows the maximum growth rates for $V=0$ and for a realistic Kuroshio flow. In the ECS, these errors are still small compared to the expected growth rates.

\section{c. Background states}

The most important preliminary step in preparing the model was defining a suitable background state. The chosen basic background state was based on a "snapshot" of the Kuroshio cross section rather than an average mean state in order to preserve spatial gradients. This snapshot was provided by hydrographic sections and ADCP data (as well as hydrographic data) from the October 1992 cruise (Fig. 2).

Using the thermal wind relationship (1) to determine vertical shear from the density sections, it was possible to estimate an absolute $V$ field by using the ADCP- derived velocities from 10-m depth and integrating the vertical shear from this level. The smoothed background-state density field and the derived velocity field are shown in Fig. 10a. The recirculation jet over the continental slope appears to be real; it has been observed in previous Kuroshio sections near this location by Chen et al. (1992) in January 1986, Ichikawa and Beardsley (1993) in August 1987, and Sun and Su (1994) in May and October of 1988.

For initializing the model, an analytical representation of the basic state was used. There are two reasons for this. First, a suitably chosen analytic form allows wellbehaved extrapolation beyond the region of existing observations. This is important because the observed basic state is only $174 \mathrm{~km}$ wide and the front is still present at the western edge of our observations (Fig. 10a). Second, an analytical function can be differentiated in the vertical. This allows computation of the density field without finite difference errors.

The analytical function for $V$ was a combination of a function representing the velocity core and three shaping functions to reproduce local features. The velocity core was based on a profile suggested by Xue:

$$
\begin{aligned}
V_{c}(x, z) & =V_{0} \exp \left(\frac{z}{Z_{e}}\right) \exp \left[-\left(\frac{x-X_{c 0}-Z_{m} z}{L}\right)^{2}\right] \\
L & =\frac{L_{w}}{4}\left[5+\tanh \left(\frac{x-X_{c 0}}{L_{w}}\right)\right] .
\end{aligned}
$$

The shaping functions included two barotropic jets, modeled with Gaussian profiles, and one two-dimensional Gaussian jet:

$$
\begin{aligned}
G_{1}(x) & =A_{1} \exp \left[-\left(\frac{x-X_{c 1}}{X_{w 1}}\right)^{2}\right] \\
G_{2}(x) & =A_{2} \exp \left[-\left(\frac{x-X_{c 2}}{X_{w 2}}\right)^{2}\right] \\
G_{3}(x, z) & =A_{3} \exp \left[-\left(\frac{x-X_{c 3}}{X_{w 3}}\right)^{2}-\left(\frac{z-Z_{c 3}}{Z_{w 3}}\right)^{2}\right] .
\end{aligned}
$$

A constant $\left(V_{b g}\right)$ was added to represent a uniform background flow. The resulting analytical velocity was then forced to zero at the boundaries by multiplying with a high-order Gaussian:

$$
\begin{aligned}
V(x, z)= & \left(V_{c}+G_{1}+G_{2}+G_{3}+V_{b g}\right) \\
& \times \exp \left[-\left(\frac{x-167 \mathrm{~km}}{110 \mathrm{~km}}\right)^{8}\right]
\end{aligned}
$$

All 17 unspecified parameters were determined by nonlinear least squares fitting in which the mean square of the difference between this analytical $V(x, z)$ and the observed $V(x, z)$ was minimized over the domain of the observations. The resulting analytical function is plotted 

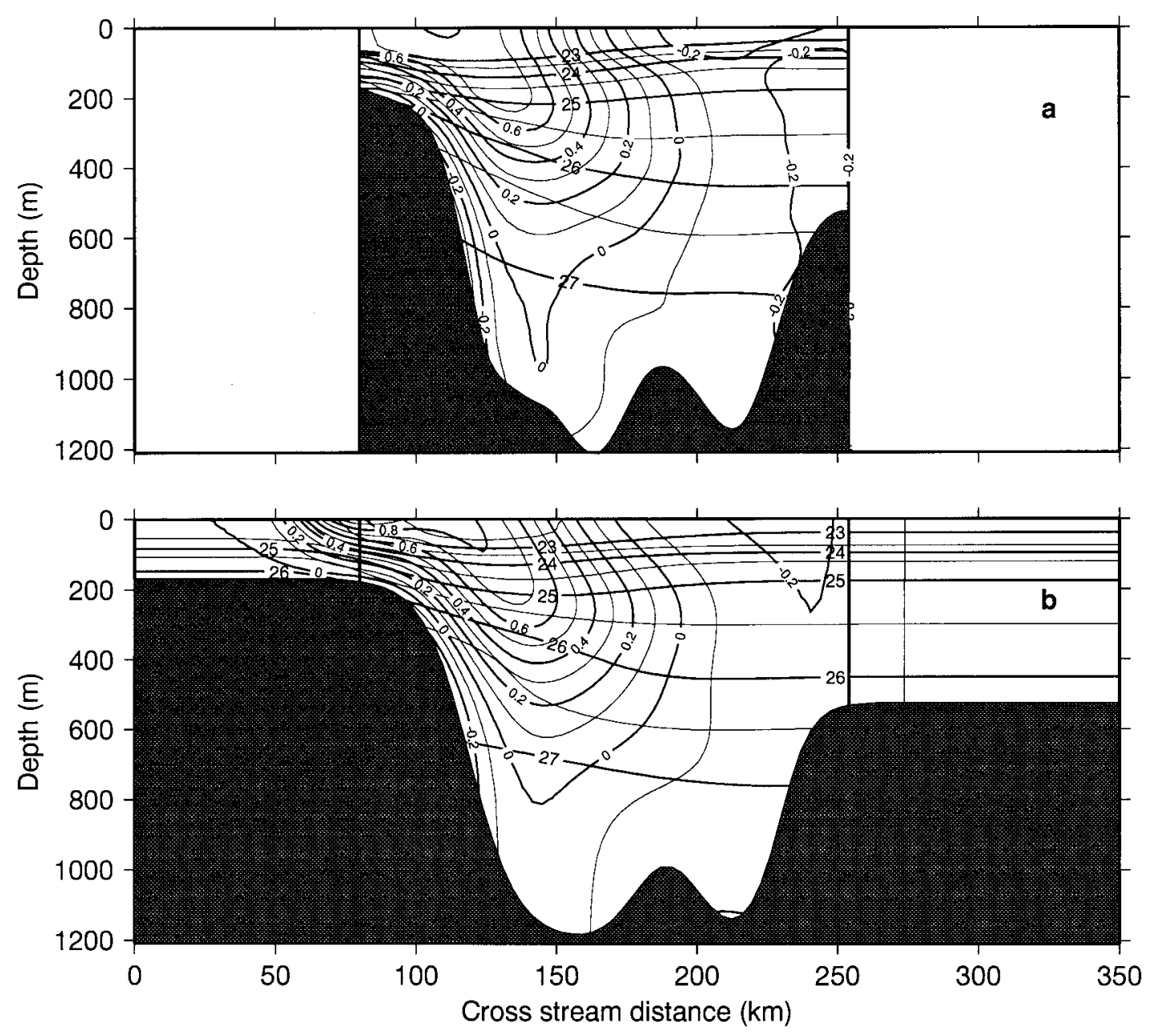

FIG. 10. Filtered background state and topography (a) as observed, and (b) as represented by the analytical functions (26) and (30). The vertical bars at 80 and $254 \mathrm{~km}$ indicate the horizontal limits of the observations. Velocity is in $\mathrm{m} \mathrm{s}^{-1}$; contour interval $0.1 \mathrm{~m} \mathrm{~s}^{-1}$. Density is given as $\sigma_{t}$; contour interval $0.5 \mathrm{~kg} \mathrm{~m}^{-3}$.

in Fig. 10b. In regions where observations were lacking, the analytical background is consistent with other observed profiles from the area (Chen et al. 1992; Ichikawa and Beardsley 1993; Sun and $\mathrm{Su}$ 1994). In addition, the transport computed from the analytical background is $20 \mathrm{~Sv}$, only $16 \%$ less than the $23.7 \mathrm{~Sv}$ mean value of Ichikawa and Beardsley (1993) for the Kuroshio in the ECS.

The density structure was determined by analytically differentiating the velocity function in the vertical and using the thermal wind relationship (1) to determine $\partial \rho /$ $\partial x$. The density gradient was numerically integrated in the horizontal from east to west, using the measured density structure observed along the eastern boundary to reference the integration. The resulting density field is shown in Fig. 10b.

Because the model requires determination of the topographic gradient in the $x$ direction, we formed an analytical function to represent the topography. This function is

$$
\begin{aligned}
& H_{e}(x)=H_{s e}+\frac{1}{2}\left(H_{d}-H_{s e}\right)\left[1+\tanh \left(\frac{x-X_{c e}}{\alpha_{e}}\right)\right] \\
& H_{w}(x)=H_{s w}+\frac{1}{2}\left(H_{d}-H_{s w}\right)\left[1-\tanh \left(\frac{x-X_{c w}}{\alpha_{w}}\right)\right] \\
& H_{b}(x)=-H_{s b} \exp \left[-\left(\frac{x-X_{c b}}{\alpha_{b}}\right)^{2}\right]-H_{d} \\
& h(x)=H_{e}+H_{w}+H_{b} .
\end{aligned}
$$

All 10 unspecified parameters were determined by nonlinear least squares fitting to the known bathymetry. The resulting topography is also plotted in Fig. $10 \mathrm{~b}$.

This basic background state is called the $K_{I}$ state. A necessary condition for barotropic and baroclinic instability in a vertically and horizontally sheared flow is that the product of the potential vorticity gradient and the velocity must be positive somewhere (Pedlosky 
1964). Based on this condition, the $K_{I}$ basic state has been shown to be potentially unstable to both barotropic and baroclinic instabilities (James 1996), and therefore suitable for study using this model. A somewhat similar basic state for the Gulf Stream south of the Charleston Bump, used by Xue and Mellor (1993), is designated $\mathrm{GS}_{\mathrm{I}}$ (but called $I_{1}$ by Xue and Mellor 1993). In addition to the basic $\mathrm{K}_{\mathrm{I}}$ state, established from the observational Kuroshio data, we consider several variations on this state in order to investigate the influence of various features of the flow and topography on the instability properties. In each of these variations, just one feature of the $\mathrm{K}_{\mathrm{I}}$ state is altered. In four of the variations, a parameter is altered to make a particular feature of the background state resemble the Gulf Stream $\mathrm{GS}_{\mathrm{I}}$ state: the shelf depth is reduced from 167 to $50 \mathrm{~m}$ in the $\mathrm{K}_{\mathrm{SD} 50}$ state; the velocity field is scaled up to raise the transport from 20 to $33 \mathrm{~Sv}$ in the $\mathrm{K}_{\mathrm{T} 33}$ state; the entire velocity field is shifted $10 \mathrm{~km}$ in the offshelf direction in the $\mathrm{K}_{\mathrm{X} 10}$ state; the offshore Ryukyu Ridge is eliminated in the $\mathrm{K}_{\mathrm{NR}}$ state. In one other background-state variation, the shelf width is increased from 100 to $200 \mathrm{~km}$. These various Kuroshio background states are shown in Fig. 11.

\section{Model results and discussion}

The characteristics of model instability modes were calculated for a range of wavenumbers corresponding to wavelengths between 105 and $1257 \mathrm{~km}$. In each case, the described wave properties are those of the mode with the fastest growth rate at its fastest-growth wavenumber. In particular, the model is used to give us the wavelength $(2 \pi / \beta)$, period $\left(2 \pi /\left|\sigma_{r}\right|\right)$, downstream phase velocity $\left(-\sigma_{r} / \beta\right)$, and growth rate $\left(-\sigma_{i}\right)$ of this instability. The model also provides the spatial structures of the velocity $(u, v, w)$ and buoyancy $(b)$ perturbation fields and of the energy-transfer terms. There are three energy-transfer terms: mean-to-eddy kinetic energy, or Reynolds stress (RS); mean-to-eddy potential energy, or horizontal heat flux (HHF); and eddy potential energy to eddy kinetic energy, or vertical heat flux (VHF). Xue and Mellor (1993) define these terms and discuss their significance.

\section{a. The Kuroshio basic background state}

For the Kuroshio basic state (Fig. 11a), the model predicts a peak growth rate at a period of 12 days, close to the energetic 11-day peak in the observed EOF spectrum (Fig. 4). The model-predicted wavelength is 209 $\mathrm{km}$, consistent with the observed $217 \pm 44 \mathrm{~km}$. The phase velocities are also close: 18 and $20 \pm 4 \mathrm{~km}_{\text {day }}{ }^{-1}$, respectively. This agreement is encouraging and suggests that the model is reproducing a realistic instability at this period.

A separate confirmation comes from the results of the EOF analysis illustrated in Fig. 12. The IES records may be interpreted as representing full-water-column dynamic height variations,

$$
\int_{0}^{p_{b}}-\frac{g}{\rho_{0}} \frac{1}{B+b} d p,
$$

where $p_{b}$ is pressure near the sea floor. Since $b \ll B$, these variations are proportional to

$$
\int_{0}^{p_{b}} b d p .
$$

Hence fluctuations in the IES record should be proportional to fluctuations in the vertically integrated $b$ field. Figure 12 shows both the first-mode EOF spatial function from our IES measurements and the vertically integrated $b$ field from the model of the Kuroshio basic background state. Note that the first-mode EOF is the same as that in Fig. 6 but rescaled to give full-watercolumn (rather than 0-500 db) dynamic height, as in Eq. (32). The agreement in shape between these two functions in Fig. 12 suggests that the model is reproducing the observed instability. Spatial structures of the perturbation fields and energy-transfer terms are shown in Fig. 13. It is clear that all of these perturbations ( $u$, $v, b)$ and energy transfers (RS, HHF, VHF) are strongest over the outer shelf, about $30-40 \mathrm{~km}$ from the shelf break.

Our observed spectrum (Fig. 4) shows additional peaks at 16 and 7 day periods. Possible explanations of these will be discussed in section $4 \mathrm{c}$ after we have considered, in the next section, the effects of backgroundstate variations on the resulting instability.

\section{b. Background-state variations}

The model was run for the various alternate background states described at the end of section $3 \mathrm{c}$. The results are summarized in Table 3 and are discussed individually below. Profile $\mathrm{GS}_{\mathrm{I}}$ refers to the Gulf Stream profile from Xue and Mellor (1993).

$\mathrm{K}_{\mathrm{T} 33}$ (Fig. 11b): The higher transport of profile $\mathrm{GS}_{\mathrm{I}}$ is associated with higher-current velocity, and we would like to determine if the resulting increased advection could account for the observed increase in phase velocity. Raising the transport from 20 to $33 \mathrm{~Sv}$ by scaling the velocity profile - that is, multiplying $V(x, z)$ obtained from (26) by 1.7 -results in a $40 \%$ reduction in instability period and a $14 \%$ reduction in wavelength. The downstream phase velocity increases by $50 \%$ or $9 \mathrm{~km}$ $\mathrm{d}^{-1}=10 \mathrm{~cm} \mathrm{~s}^{-1}$, the same as the increase in surface current velocity at the point $x=51 \mathrm{~km}$ (Figs. 11a,b), which is where the disturbance is concentrated (Fig. 13). This, together with the smallness of the change in wavelength, suggests that advection is principally responsible for the increased phase velocity. The growth rate of the instability is also very high. This is presumably due to the increased velocity shear resulting in a more unstable background state. 

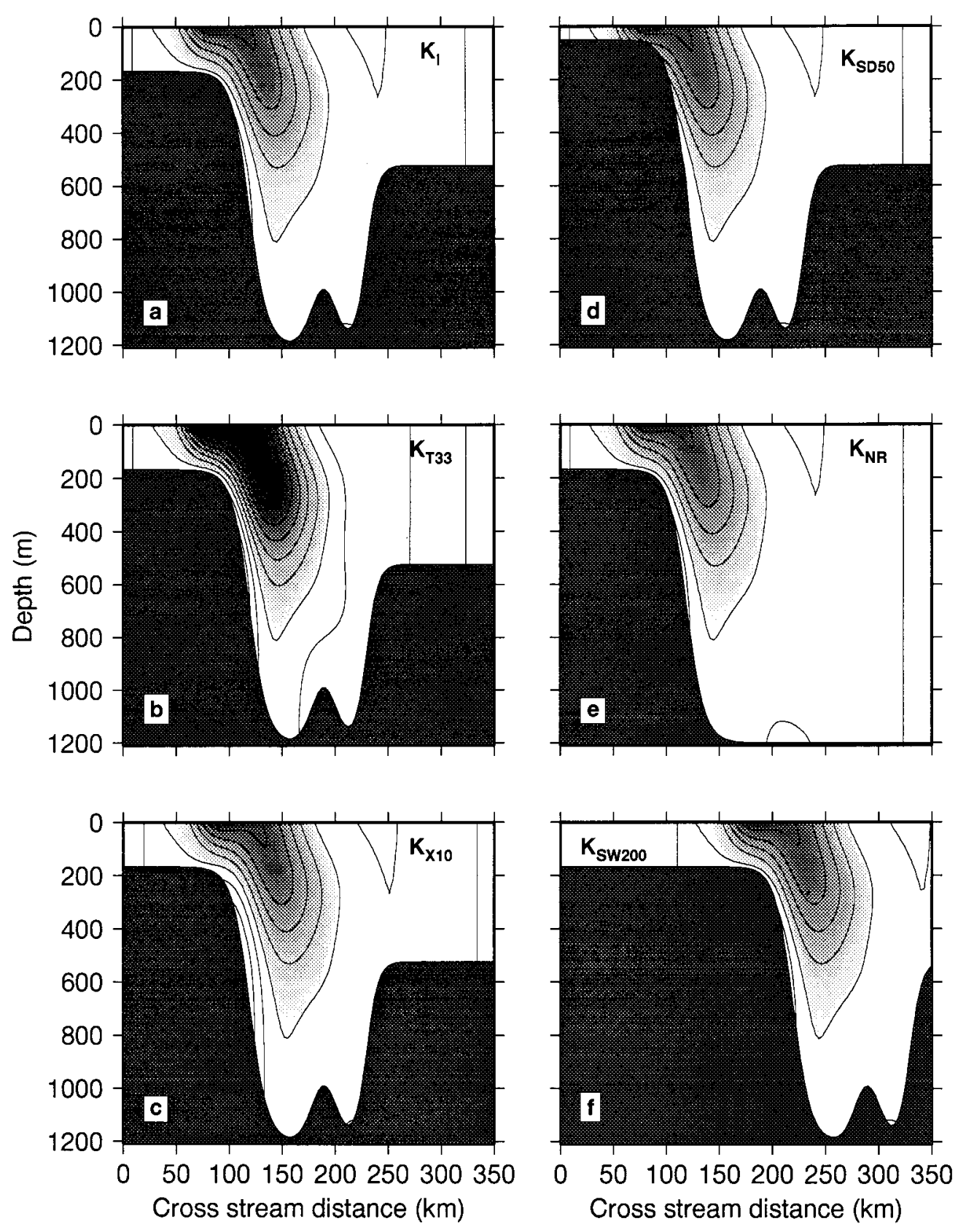

FIG. 11. Velocity field and topography of the various background states. Positive velocities (into the page) are progressively shaded. Contour interval $0.2 \mathrm{~m} \mathrm{~s}^{-1}$. (a) $\mathrm{K}_{\mathrm{I}}$ : basic state representing the Kuroshio at $28^{\circ} \mathrm{N}$ (same as Fig. 10b); (b) $\mathrm{K}_{\mathrm{T} 33}$ : transport increased to $33 \mathrm{~Sv}$; (c) $\mathrm{K}_{\mathrm{x} 10}$ : current field moved $10 \mathrm{~km}$ seaward; (d) $\mathrm{K}_{\mathrm{SD} 50}$ : shelf depth decreased to $50 \mathrm{~m}$; (e) $\mathrm{K}_{\mathrm{NR}}$ : no offshore ridge; and (f) $\mathrm{K}_{\mathrm{SW} 200}$ : shelf width increased to $200 \mathrm{~km}$.

The transport can also be raised to $33 \mathrm{~Sv}$ by appropriately scaling only the uniform barotropic flow component $V_{b g}$ in (26). In addition to the increase in downstream transport, this reduces the strength and extent of the reverse flow region. But the results are nearly the same, with an approximately $50 \%$ increase in phase velocity due to advection by the background flow (James 1996). This also implies that the intensity of the reverse flow is not an important factor in determining the phase velocity of the instability.

$\mathrm{K}_{\mathrm{X} 10}$ (Fig. 11c): The present jet of profile $\mathrm{GS}_{\mathrm{I}}$ does not move as far onto the shelf as that of the Kuroshio $\mathrm{K}_{\mathrm{I}}$ profile. Indeed the core of the Gulf Stream is located over the continental slope, about $10 \mathrm{~km}$ farther from the shelf break than the core of the Kuroshio. To investigate whether the location of the velocity profile relative to 


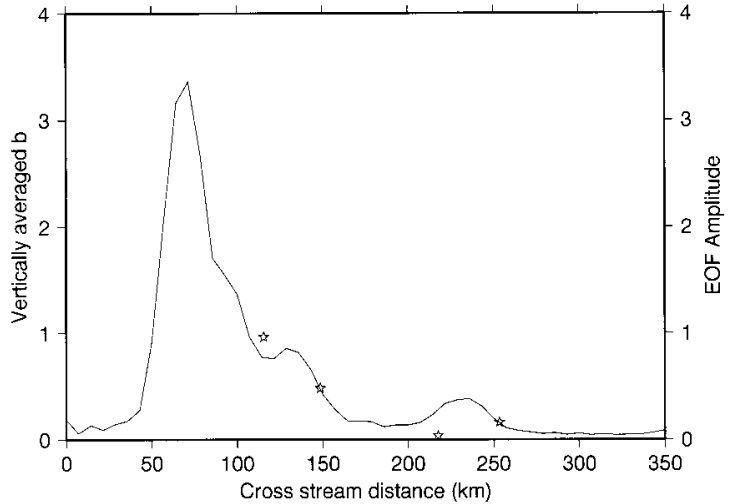

FIG. 12. First-mode EOF spatial structure of data from the crossstream IES array (stars), and vertically integrated model $b$ field for the $\mathrm{K}_{\mathrm{I}}$ basic state (solid line). EOF rescaled at the middle two sites by 1.56 to give $0-1000 \mathrm{db}$ (full water column) dynamic height (see James 1996).

the topography is important, the velocity profile in $\mathrm{K}_{\mathrm{X} 10}$ is moved $10 \mathrm{~km}$ seaward. Since the strongest perturbations are near the shelf break (Fig. 13), we may expect the instability characteristics to be sensitive to the location of the core. Indeed, this movement causes the instability period to increase over $30 \%$ and wavelength to increase $20 \%$.

The growth rate of the instability is reduced by almost $30 \%$, which indicates that this variation has a stabilizing effect. Pedlosky (1964) has shown that a sufficiently steep slope can have a stabilizing effect on a potentially unstable flow. Also the energy conversions are distributed differently from those for $\mathrm{K}_{\mathrm{I}}$. In particular there is a relatively stronger barotropic component: $\overline{\mathrm{RS}} / \overline{\mathrm{HHF}}$ is over $60 \%$ larger and $\overline{\mathrm{RS}} / \overline{\mathrm{VHF}}$ nearly $160 \%$ larger than the corresponding $\mathrm{K}_{\mathrm{I}}$ values. Using this model, Xue and Mellor (1993) found that the addition of topography had a stabilizing effect on baroclinic instabilities, although it was not clear whether this effect was due to the gradient of topography or the topography itself.

$\mathrm{K}_{\mathrm{SD} 50}$ (Fig. 11d): Another striking difference between $\mathrm{GS}_{\mathrm{I}}$ and $\mathrm{K}_{\mathrm{I}}$ is the depth of the shelf at the break. The Gulf Stream shelf depth is $50 \mathrm{~m}$; the Kuroshio shelf depth $167 \mathrm{~m}$. Since the Kuroshio instability results in perturbations that are predominantly over the shelf (Fig. 13), it is not surprising that the depth of the shelf has a strong influence on the instability. Reducing the shelf depth, $H_{s e}$ in (27), from 167 to $50 \mathrm{~m}$ results in a $60 \%$ reduction in instability period, although the wavelength is unchanged.

The growth rate increases nearly $20 \%$, indicating a more unstable flow. This is characteristic of a different topographic effect, first described by Orlanski (1969): the amplitude of topography relative to total depth can have a destabilizing effect, even while the gradient of the same topography has a stabilizing effect. The shallow shelf results in the smallest $\overline{\mathrm{RS}} / \overline{\mathrm{HHF}}$ and $\overline{\mathrm{VHF}}$ / $\overline{\mathrm{HHF}}$ ratios of any of the background states, so the en- ergy transfers are dominated by mean-to-eddy potential energy conversion, with relatively little conversion to eddy kinetic energy by either RS or VHF.

$\mathrm{K}_{\mathrm{NR}}$ (Fig. 11e): Unlike the $\mathrm{GS}_{\mathrm{I}}$ bottom topography, that of the $\mathrm{K}_{\mathrm{I}}$ state (Fig. 11a) does not deepen monotonically with offshore distance. The depth reaches nearly 1200 m near $x=160 \mathrm{~km}$, but beyond this it decreases in two stages to $523 \mathrm{~m}$ over the Ryukyu Ridge. To investigate the possible influence of this offshsore shallowing on instabilities, the bottom is modified to level off at $1200-\mathrm{m}$ depth. As a result, instability period and wavelength decrease about $15 \%$, with even smaller effects on instability growth rate and energy conversions. This is not surprising, since the strongest velocity shears are not near the Ryukyu Ridge.

$\mathrm{K}_{\mathrm{SW} 200}$ (Fig. 11f): One difficulty with the model is its inability to represent the $500-\mathrm{km}$-wide shelf present in the ECS: model convergence is too slow when the domain width is significantly increased. As a compromise we increased the model shelf width to $200 \mathrm{~km}$ by shifting the lateral boundaries shoreward by $100 \mathrm{~km}$. Fortunately, the quantities listed in Table 3 all changed by less than $15 \%$. This indicates that the model is relatively insensitive to shelf width, and that results using a 100$\mathrm{km}$ shelf width can be used with some confidence.

\section{c. Discussion}

Both field study and model results of the Kuroshio in the ECS near $28^{\circ} \mathrm{N}$ show oscillations with 11-12-day periods, wavelength around $210 \mathrm{~km}$, and phase velocity $18-20 \mathrm{~km}$ day $^{-1}$ downstream. Similarly, measurements and model results of the Gulf Stream off northern Florida show oscillations with period around 5 days, wavelength around $215 \mathrm{~km}$, and phase velocity around $40 \mathrm{~km}$ day $^{-1}$ downstream. Thus, while the wavelength appears the same in the two currents, the Gulf Stream period is only half that of the Kuroshio, and consequently the phase velocity is twice that of the $\mathrm{Ku}$ roshio.

The $\mathrm{GS}_{\mathrm{I}}$ Gulf Stream background state, Fig. 3a in Xue and Mellor (1993), differs from our $K_{I}$ Kuroshio background state in both its current field and its topography. The Gulf Stream current has a transport $65 \%$ higher and a velocity core $10 \mathrm{~km}$ farther over the slope than the Kuroshio. The continental shelf near the Gulf Stream (off northern Florida) has only 30\% of the depth and width of the continental shelf near the Kuroshio (off China); also, the Gulf Stream has no seaward ridge (north of the Bahama Banks) while the Kuroshio in the ECS has the Ryukyu Ridge on its seaward side. It is interesting to consider which of these differences have important effects on the different characteristics of the instabilities in these two regions.

From the results reported in the previous section, it at first appears that the reduced shelf depth alone could account for the Gulf Stream oscillation's shorter period and similar wavelength (hence higher phase velocity). 

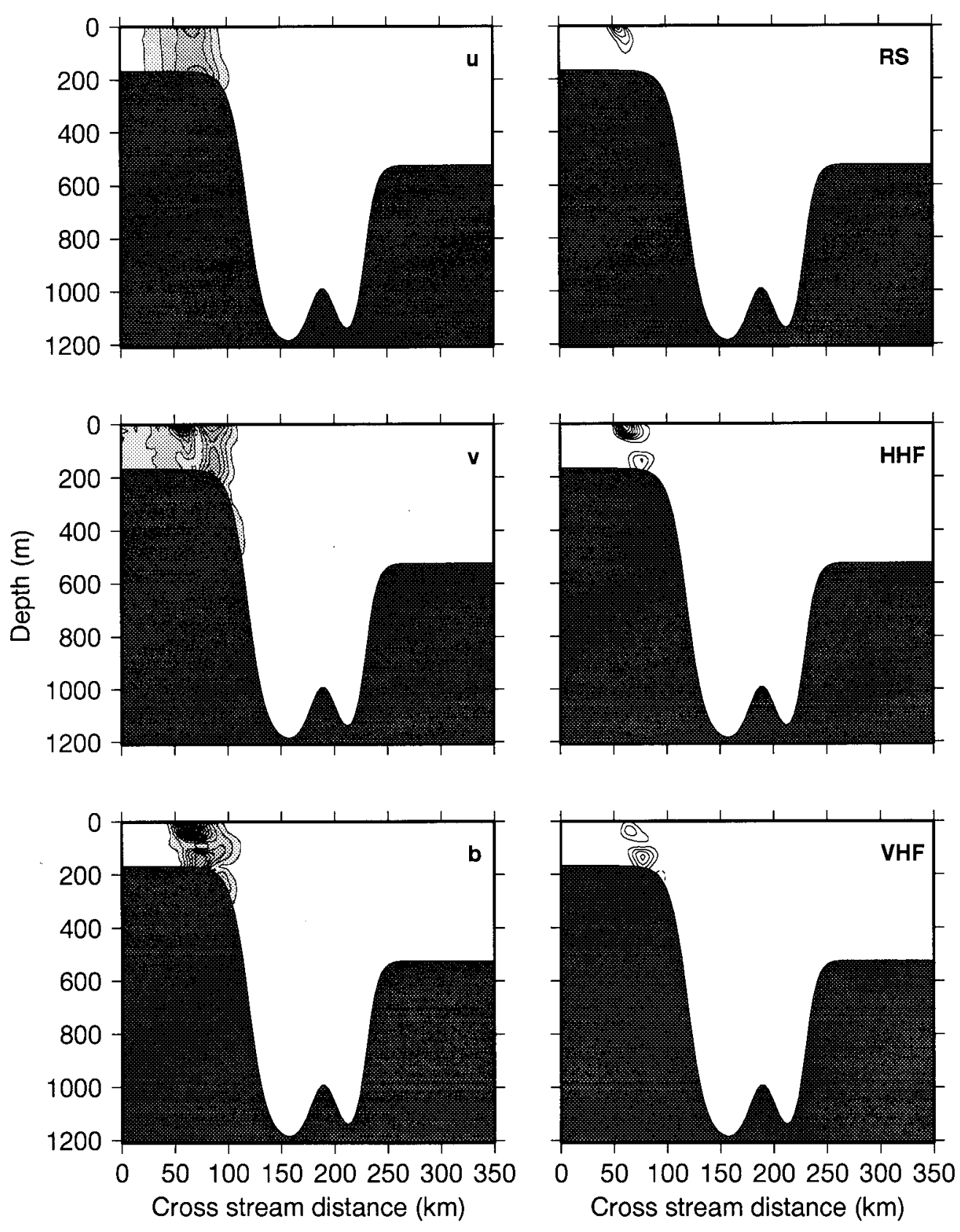

FIG. 13. Perturbation fields (left) and energy-transfer terms (right) for the $\mathrm{K}_{\mathrm{I}}$ basic state. Contour interval for $b$ is twice that for $v$ and $u$; darker shading signifies higher amplitude. Contour interval for HHF is twice that for RS and VHF; dashed contour indicates a negative value; and the zero contour in the energy conversion plots is omitted for clarity.

But in reality a reduced shelf depth would presumably "squeeze" the current and shift it seaward, bringing about an increase in the period. Nevertheless, the 13$\mathrm{Sv}$ increased transport of the actual Gulf Stream apparently results in effects that more or less counteract the effects of the 10-km seaward shift of the Gulf Stream current. The effects of the other two factors (shelf width and seaward ridge) are relatively small (15\% or less).

Our model results show a 0.47 day $^{-1}$ growth rate for the fastest growing $\mathrm{K}_{\mathrm{I}}$ instability, which is $34 \%$ higher than the 0.35 day $^{-1}$ growth rate for the Gulf Stream $\mathrm{GS}_{\text {I }}$ state (Xue and Mellor 1993). This may be due to the Gulf Stream being positioned more over the slope than the Kuroshio. Pedlosky (1964) shows that a sufficiently steep slope in the bottom topography can have a stabilizing effect on potentially unstable flow. Xue and Mellor also demonstrate that the addition of topography to the model has a stabilizing effect on baroclinic in- 
TABLE 3. Parameters defining different background states (first five rows) and their model results (bottom six rows), for the basic Kuroshio state $K_{1}$ and five variations and for the Gulf Stream state $\mathrm{GS}_{\mathrm{I}}\left(\mathrm{I}_{1}\right.$ in Xue and Mellor 1993). Boldface numbers indicate distinguishing parameters of the Kuroshio background state variations.

\begin{tabular}{|c|c|c|c|c|c|c|c|}
\hline & $\mathrm{K}_{\mathrm{I}}$ & $\mathrm{K}_{\mathrm{T} 33}$ & $\mathrm{~K}_{\mathrm{x} 10}$ & $\mathrm{~K}_{\mathrm{SD} 50}$ & $\mathrm{~K}_{\mathrm{NR}}$ & $\mathrm{K}_{\mathrm{SW} 200}$ & $\mathrm{GS}_{\mathrm{I}}$ \\
\hline Transport (Sv) & 20 & 33 & 20 & 20 & 20 & 20 & 32 \\
\hline Core location $(\mathrm{km})$ & 82 & 82 & 92 & 82 & 82 & $82+100$ & 110 \\
\hline Shelf depth (m) & 167 & 167 & 167 & 50 & 167 & 167 & 50 \\
\hline Offshore ridge & yes & yes & yes & yes & no & yes & no \\
\hline Shelf width $(\mathrm{km})$ & 100 & 100 & 100 & 100 & 100 & 200 & 100 \\
\hline Growth rate $\left(\right.$ day $\left.^{-1}\right)$ & 0.47 & 0.83 & 0.34 & 0.56 & 0.43 & 0.47 & 0.35 \\
\hline Period (day) & 12 & 7 & 16 & 5 & 10 & 11 & 5 \\
\hline Wavelength $(\mathrm{km})$ & 209 & 180 & 251 & 209 & 180 & 180 & 215 \\
\hline Phase velocity $\left(\mathrm{km} \mathrm{day}^{-1}\right)$ & 18 & 27 & 15 & 40 & 19 & 16 & 39.3 \\
\hline$\overline{\mathrm{RS}} / \overline{\mathrm{HHF}}$ & 0.19 & 0.19 & 0.31 & 0.11 & 0.17 & 0.21 & 0.56 \\
\hline$\overline{\mathrm{VHF}} / \overline{\mathrm{HHF}}$ & 0.30 & 0.40 & 0.19 & 0.09 & 0.32 & 0.33 & 0.30 \\
\hline
\end{tabular}

stabilities. The relatively low growth rate of 0.34 day $^{-1}$ of the $\mathrm{K}_{\mathrm{X} 10}$ state supports this interpretation.

The oscillating spring may be a useful analog for the topographic influences on the current system. Increased "stiffness" (resistance to meandering) results in shorterperiod oscillations. Decreasing the shelf depth makes it harder for the flow to move shoreward, thus increasing this stiffness. On the other hand, moving the core of the current seaward makes it easier for the flow to meander and reduces the stiffness. This accounts for the shorter periods observed for $\mathrm{K}_{\mathrm{SD} 50}$ and the longer periods for $\mathrm{K}_{\mathrm{X} 10}$.

What about the two other peaks in the observed $\mathrm{Ku}$ roshio spectrum at 7 and 16 day periods? Although there is a spectral peak at the 7-day period in the overall spectrum (Fig. 4), there appears to be very little 7-day energy when the background-state measurements were made, near the end of the IES record (Fig. 5). So we do not expect our model results to reproduce this instability. According to Table 3, an instability with period 7 days and phase velocity $27 \mathrm{~km} \mathrm{day}^{-1}$ is dominant when the transport increases to $33 \mathrm{~Sv}$. These characteristics are close to those observed (6.9 days, $28.2 \mathrm{~km}$ day $^{-1}$ ). Also, $33 \mathrm{~Sv}$ transport during the period of strong 7-day oscillations (February 1992, according to Fig. 5) is not unreasonable since in this region Kaneko et al. (1990) measured 27.2 Sv and Kaneko et al. (1993) measured 25.5-28.1 Sv while Ichikawa and Beardsley (1993) observed Kuroshio transports up to $46.8 \mathrm{~Sv}$. The 16-day oscillations are present not only in the overall spectrum (Fig. 4) but also at the end of the field study (Fig. 5) when the background-state measurements were made. Nevertheless, this instability does not appear in our model results. According to Table 3, an instability with a 16-day period and $15 \mathrm{~km} \mathrm{day}^{-1}$ phase velocity would be dominant if the Kuroshio flow were $10 \mathrm{~km}$ seaward of its position in the observed background state. These characteristics are close to those observed (15.9 day, $16.7 \mathrm{~km} \mathrm{day}^{-1}$ ). Perhaps these oscillations are generated upstream of our observation line and advected into the region. Figure 1 shows the mean path of the Kuroshio farther offshore upstream of our site, so there is clearly the potential for generation of 16-day waves, given that the shelf-edge depth is relatively constant along the ECS.

\section{Conclusions}

Kuroshio meanders in the ECS have much smaller amplitude than those farther downstream. One therefore expects the results of small-amplitude perturbation theory may be applicable to the actual instabilities in the ECS. The modeling work presented here is based on this assumption, which appears to be justified by the results for the 11-12-day wave. The phase velocities are consistent with observations, from this and previous studies, that Kuroshio meanders in the ECS propagate at about $20 \mathrm{~km} \mathrm{day}^{-1}$, half the speed of Gulf Stream meanders at similar latitudes (Table 1).

Based on the model results, some conclusions may be drawn about the nature of the 11-12-day wave. The fastest-growing Kuroshio instability is located over the continental shelf, while that of the Gulf Stream is over the slope (Xue and Mellor 1993). The energetics show a predominantly baroclinic instability (Table 3 ). Baroclinic conversion is also dominant in the Gulf Stream, but, as Table 3 shows, the barotropic conversion is proportionally weaker in the Kuroshio than in the Gulf Stream. The Kuroshio instability waves have about half the phase velocity and twice the period of the corresponding Gulf Stream waves. The principal factors responsible for these differences are the Kuroshio's greater shelf depth, core location more over the shelf, and lesser transport. The effects of shelf depth and core location on meander period may be attributed to their effects on the "stiffness" of the system. Transport's main influence on phase velocity may be attributed to its advection of the instability.

Our measurements also show oscillations with periods of 7 and 16 days, but their dynamics are less certain. We speculate that they are respectively the results of intermittent increases in Kuroshio transport and offshore shifts in its position. 
Acknowledgments. The efforts of the captains and crews of the T/V Keiten-maru and T/V Kagoshimamaru were essential to the success of the cruises. Michael Mulroney was responsible for the preparation, deployment, and recovery of the IES's. Shiro Imawaki and Toru Yamashiro helped much during the 1991 cruise for the deployment of the instruments. Professors Masaaki Chaen and Akio Maeda of Kagoshima University encouraged this study. Huijie Xue generously gave us the computer code for her model and much helpful advice. The model was run using the resources of the Cornell Theory Center, which receives major funding from the National Science Foundation and New York State with additional support from the Advanced Research Projects Agency, the National Center for Research Resources at the National Institutes of Health, IBM Corporation, and members of the Corporate Research Institute. The work of Charles James and Mark Wimbush was supported by the National Science Foundation (NSF) and the Office of Naval Research (ONR) through NSF Grant OCE9018581 and ONR Grant N00014-94-10023. The participation of Hiroshi Ichikawa was covered by the Ministry of Education, Science, and Culture, Japan. The data analysis and model work was carried out as part of James's dissertation.

\section{REFERENCES}

Bane, J. M., and D. A. Brooks, 1979: Gulf Stream meanders along the continental margin from the Florida Straits to Cape Hatteras. Geophys. Res. Lett., 6, 280-282.

Bingham, C., M. Godfrey, and J. Tukey, 1967: Modern techniques of power spectrum estimation. IEEE Trans. Audio Electroacoust., AU-15, 56-66.

Chen, C., R. C. Beardsley, and R. Limeburner, 1992: The structure of the Kuroshio southwest of Kyushu: velocity, transport and potential vorticity fields. Deep-Sea Res., 39, 245-268.

Ichikawa, H., 1993: Short period variations of the Kuroshio volume transport in the East China Sea. Umi to Sora, 69, 135-148.

— , and R. C. Beardsley, 1993: Temporal and spatial variability of volume transport of the Kuroshio in the East China Sea. DeepSea Res., 40, 583-605.

James, C., 1996: Kuroshio instabilities in the East China Sea-Observations, modeling, and comparison with the Gulf Stream. $\mathrm{Ph} . \mathrm{D}$. thesis, University of Rhode Island, $150 \mathrm{pp}$.

—, and M. Wimbush, 1995: Inferring dynamic height variations from acoustic travel time in the Pacific Ocean. J. Oceanogr., 51, $553-569$.

- - , and H. Ichikawa, 1994: East China Sea, Kuroshio 199192 data report, Graduate School of Oceanography Tech. Rep. 94-3, 22 pp. [Available from Graduate School of Oceanography, University of Rhode Island, Narragansett, RI 02882.]

Kaneko, A., W. Koterayama, H. Honji, S. Mizuno, K. Kawatate, and R. Gordon, 1990: Cross-stream survey of the upper $400 \mathrm{~m}$ of the Kuroshio by an ADCP on a towed fish. Deep-Sea Res., 37, $875-889$.

_, N. Gohda, W. Koterayama, M. Nakamura, S. Mizuno, and H. Furukawa, 1993: Towed ADCP fish with depth and roll controllable wings and its application to the Kuroshio observation. J. Oceanogr., 49, 383-395.

Kontoyiannis, H., and D. R. Watts, 1994: Observations on the variability of the Gulf Stream path between $74^{\circ} \mathrm{W}$ and $70^{\circ} \mathrm{W} . J$. Phys. Oceanogr., 24, 1999-2013.

Lee, T. N., and L. P. Atkinson, 1983: Low-frequency current and temperature variability from Gulf Stream frontal eddies and atmospheric forcing along the southeast U.S. outer continental shelf. J. Geophys. Res., 88, 4541-4567.

Moore, G. W. K., and W. R. Peltier, 1987: Cyclogenesis in frontal zones. J. Atmos. Sci., 44, 384-409.

Orlanski, I., 1969: The influence of bottom topography on the stability of jets in a baroclinic fluid. J. Atmos. Sci., 26, 1216-1232.

Pedlosky, J., 1964: The stability of currents in the atmosphere and the ocean: Part I. J. Atmos. Sci., 21, 201-219.

Preisendorfer, R. W., 1988: Principal Component Analysis in Meteorology and Oceanography. Elsevier, 425 pp.

Qiu, B., T. Toda, and N. Imasato, 1990: On Kuroshio front fluctuations in the East China Sea using satellite and in situ observational data. J. Geophys. Res., 95, 18 191-18 203.

Richardson, W. S., W. J. Schmitz, and P. N. Niiler, 1969: The velocity structure of the Florida Current from the Straits of Florida to Cape Fear. Deep-Sea Res., 16 (Suppl.), 225-231.

Sugimoto, Y., S. Kimura, and K. Miyaji, 1988: Meander of the Kuroshio front and current variability in the East China Sea. $J$. Oceanogr. Soc. Japan, 44, 125-135.

Sun, X.-P., and Y.-F. Su, 1994: On the variation of Kuroshio in East China Sea. Oceanology of China Seas, D. Zhou, Y.-B. Liang, and C. K. Tseng, Eds., Vol. 1, Kluwer Academic, 49-58.

Trivers, G., and M. Wimbush, 1994: Using acoustic travel time to determine dynamic height variations in the North Atlantic Ocean. J. Atmos. Oceanic Technol., 11, 1309-1316.

Wallace, J. M., and R. E. Dickinson, 1972: Empirical orthogonal representation of time series in the frequency domain. Part I: Theoretical considerations. J. Appl. Meteor., 11, 887-892.

Watts, D. R., and H. T. Rossby, 1977: Measuring dynamic heights with inverted echo sounders: Results from MODE. J. Phys. Oceanogr., 7, 345-358.

Xue, H., 1991: Numerical studies of Gulf Stream meanders in the South Atlantic Bight. Ph.D. thesis, Princeton University, 188 pp. , and G. Mellor, 1993: Instability of the Gulf Stream front in the South Atlantic Bight. J. Phys. Oceanogr., 23, 2326-2350. 